\title{
HORIZONS AND CHALLENGES
}

It is with great honor that we inform you, readers and contributors, that the responsibility for the scientific editing of História, Ciências, Saúde - Manguinhos (HCSM) was placed in our hands in March 2015. For many years, Jaime L. Benchimol was at the helm of what has become one of the most prominent vehicles for disseminating research on the history of science, medicine, and public health in Brazil and - we dare say - Latin America. This success is due in great part to Jaime's broad vision and his dedicated leadership of the journal, which he shaped into a space for true transdisciplinary collaboration and the discussion of contemporary topics from a historical perspective. Moreover, Jaime wisely surrounded himself with skilled teams, both at the "workshop" where the journal is edited and on the editorial board, and he was adept at drawing the collaboration of peer reviewers and authors.

Today HCSM is indexed by major international databases like Scopus, PubMed, and Web of Science. Since 2013, it has been active on social networks and has maintained a blog in Portuguese and English (www.facebook.com/revistahcsm; http://www.twitter.com/ revistahcsm; www.revistahcsm.coc.fiocruz.br). Thanks to these multiple tools and myriad resources, we are well positioned to advance science communication and engage in exchange with a variety of audiences. The journal's endeavor to share content and information on current topics within its scope of interest forms part of a broader enterprise to tighten the ties between academic production and our public. Challenges inherent to our contemporary world loom on the horizon. We are now witnessing a lively debate about the internationalization of scientific production. Researchers, funding agencies, editors, and websites alike are busy discussing the best strategies for accomplishing this goal. We believe HCSM can make a valuable contribution to this debate through its advocacy of open access - yet another of Jaime's contributions, and a mark of the journal - in tandem with other publications currently under the umbrella of the Scientific Electronic Library Online (SciELO). We mean to preserve this legacy through active participation in discussion forums on how to keep scientific journals in tune with new times.

We will continue to enforce the general lines of the editorial policy that Jaime put in place over the years. The editorial board will suffer only minor changes, and these will be in response to the demands of internationalization while also meant to more faithfully reflect the regional, thematic, disciplinary, and institutional diversities specific to our academic scenario. Additionally, we will begin preparing ourselves for HCSM's anniversary in 2019, when the journal will commemorate 25 years of uninterrupted publication. This symbolic 
date gives us a good reason to commence trading ideas with other editors and researchers about both the relevance and the challenges of publishing academic journals in the fields of history and the human and social sciences in South America.

We are coming onboard as scientific editors right when HCSM is implementing an online submission system through ScholarOne Manuscripts, a resource SciELO has made available to modernize the editorial process. We trust that the system will allow us to enhance and better coordinate our work with authors, associate and department editors, and peer reviewers. The moment also coincides with the development of a website of Fiocruz periodicals (www. periodicos.fiocruz.br). This laudable initiative - undertaken by the Oswaldo Cruz Foundation's Office of the Vice President of Teaching, Information, and Communication - will compile in one virtual space scholarship released by the institution. We also intend to increase our own virtual presence, something that has already proven vital to dialogue with authors and readers.

We would like to thank Jaime Benchimol and the directors of the Casa de Oswaldo Cruz for entrusting us with the mission of moving the journal forward. We hope we can count on the loyalty of our readers, peer reviewers, and contributors, which is what has made HCSM the top-quality journal it is today. Sustaining this level of academic excellence will demand your endorsement, your critical voice, and your support.

Happy reading!

Marcos Cueto

André Felipe Cândido da Silva 